\title{
Not as pure as snow
}

\author{
DAN WHIPPLE
}

\begin{abstract}
Wind-blown dust from the Southwest US is shortening seasonal snow cover in Colorado's ski resorts.
\end{abstract}

Snow cover, it appears, is not as pure as the driven snow. A recent paper in Geophysical Research Letters ${ }^{1}$ found that dust blown up from the Colorado Plateau in the American Southwest is accelerating snowmelt hundreds of miles away in the San Juan Mountains.

An earlier snowmelt is not just a cosmetic issue in the American West, where the ski industry is an irreplaceable attraction for tourists. Snowpack provides late season water supplies for irrigation, livestock watering and for the millions inhabiting cities such as Los Angeles, Phoenix and Denver.

Now, Tom Painter, of the University of Colorado's Snow and Ice Data Center and colleagues have found that snowmelt can occur almost a month earlier than usual under dry conditions as a result of dust blown in from the Four Corners area of Colorado, Arizona, Utah and New Mexico. Previous studies have shown that dust absorbs solar radiation and increases snowmelt ${ }^{2}$, but this is the first to quantify dust cover and rates of melt in situ.

\section{There will be a drying and warming in the southwest United States. This leads us to think that we may get greater dust emissions in the future. \\ Tom Painter}

\section{SNOWBALL EFFECT}

Snow has the highest albedo, or reflectivity, of any naturally occurring surface on earth. The albedo of pure white snow is 0.92 , meaning that it reflects back into the atmosphere roughly $92 \%$ of the energy it receives. As the snow extent declines, the earth absorbs more heat, rather than reflecting it back into space, which in turn speeds melting.

Painter's group measured 2005-2006 snowmelt at two locations in the San

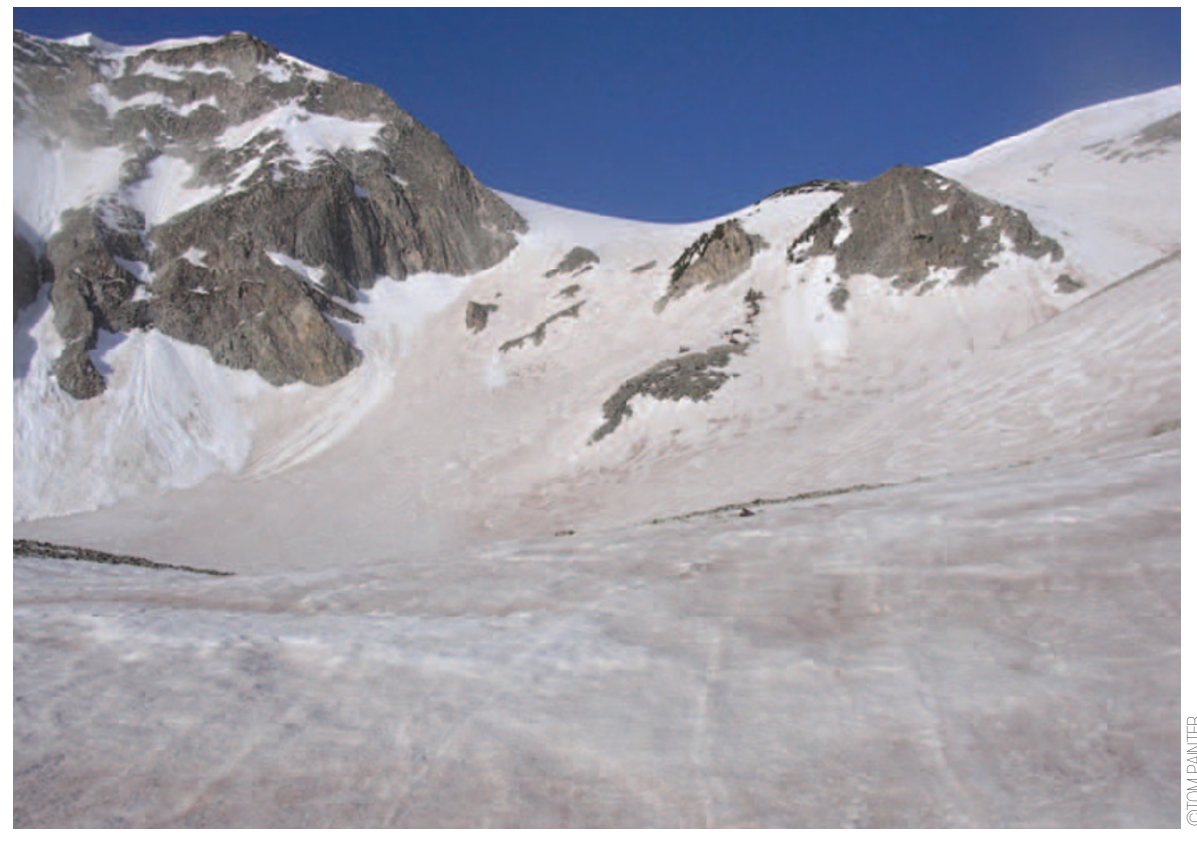

The Colorado Mountains, where the ski industry is an irreplaceable attraction for tourists.

Juan mountains - one alpine and one subalpine - and compared the observed dates of melting with predictions of the aptly named snow energy balance model, or SNOBAL. The researchers found that snow albedo dropped dramatically in two periods of the winter and spring of 2005 from 0.85 to 0.45 in the subalpine region and to 0.51 in the alpine region. There were similar, though smaller, declines in albedo in the 2006 season. "Snowmelt simulations indicate that in 2005 the subalpine snow melted out 22 to 32 days earlier and alpine snow cover melted out 23 to 33 days earlier than dust free snow," say the authors. There was less snow in 2006, with the effect that snow cover melted even faster under the influence of the dust events.

\section{WEAKEST LINK}

David Robinson, a climatologist with New Jersey's Rutgers University who has worked extensively on snow cover says of the influence of dust, "theoretically, it makes some sense, but observationally, that's going to be next to impossible to prove. We've seen some snowpacks darken, and the models suggest there may be some impacts, but the observation of soot, dust and dirt on snow is probably the weakest link." He notes that consistent measurements of surface albedo over large areas are lacking.

Nonetheless, Robinson says, there has been an undeniable reduction of snow cover in the northern hemisphere over the last 45 years or so. According to satellite and station observations, the extent of snow cover in the spring has declined quite significantly. There was a marked reduction in spring snow extent in the mid-1980s and it's stayed low since then, he says. During that period, snow cover decreased by about two million square kilometres, from an average of about 31.5 million to 29.5 million square kilometres. But Robinson maintains that the reasons for the reduced snow cover are uncertain. "We don't understand that completely at this point." 
Estimates of how much dust results from human activities vary widely, according to the latest report ${ }^{3}$ on the science of global warming from the Intergovernmental Panel on Climate Change. But all of the global climate models, Painter says, "show that there will be a drying and warming in the southwest United States. This leads us to think that we may get greater dust emissions in the future". Painter and colleagues say that "the phenomenon of increasing dust emissions exists beyond the western US and is global in nature". In China, for instance, the frequency of large dust storms from the Taklimakan and Gobi deserts was one event every 35 years prior to 1949. But after 1990, the events were occurring annually. Increased dust emissions are evident in Tibet and drying of the Aral Sea region has increased dust deposition in the Tien Shan, Pamir, Himalaya and Altai mountains, says Painter. In a report presented to the UN in June $e^{4}$, experts from the United Nations University said that desertification, exacerbated by climate change, represents "the greatest environmental challenge of our times".

\section{DRIER, NOT DUSTIER}

Not all lines of evidence are pointing at greater amounts of dust in the atmosphere, however, even under a warming regime. Natalie Mahowald, meteorologist at the National Center for Atmospheric Research in Boulder, Colorado, recently co-authored a paper in Atmospheric Chemistry and
Physics $^{5}$ that examines global changes in visibility resulting from dust emissions. For the Aral Sea region, one of their study sites, she says "even thought it's gotten much drier, it's not clear it's gotten much dustier".

\section{Even thought it's gotten much drier, it's not clear it's gotten much dustier. \\ Natalie Mahowald}

Mahowald maintains that it's possible, because of increased fertilization from carbon dioxide emissions, that plants will adapt rapidly to climate change, dealing better with water stress. This increase in plant vitality could result in more vegetation, thus retaining more soil and actually reducing the amount of dust. But the likely future impact of $\mathrm{CO}_{2}$ fertilization remains an open question. "What we'd really like to be able to say is, "What have humans done so far?"' Mahowald says. "But people don't tend to live in desert areas, and they don't happen to leave really good records."

\section{REFERENCES}

1. Painter, T. et al. Geophys. Res. Lett. 34, L12502 (2007). 2. Conway, H. et al. Water Resour. Res. 32, 1713-1718 (1996)

3. Working Group I Report: The Physical Basis of Climate Change (Intergovernmental Panel on Climate Change, 2007); http:// ipcc-wg1.ucar.edu/wg1/wg1-report.html

4. Adeel, Z. et al. Re-Thinking Policies to Cope with Desertification (UNU, Ontario, Canada, 2007); http://www.inweh.unu.edu/ inweh/drylands/Publications/IYDD_Policy_Brief-June_2007. pdf

5. Mahowald, N., Ballentine, J.-A., Feddema, J. \& Ramankutty, N. Atmos. Chem. Phys. 7, 3309-3337 (2007).

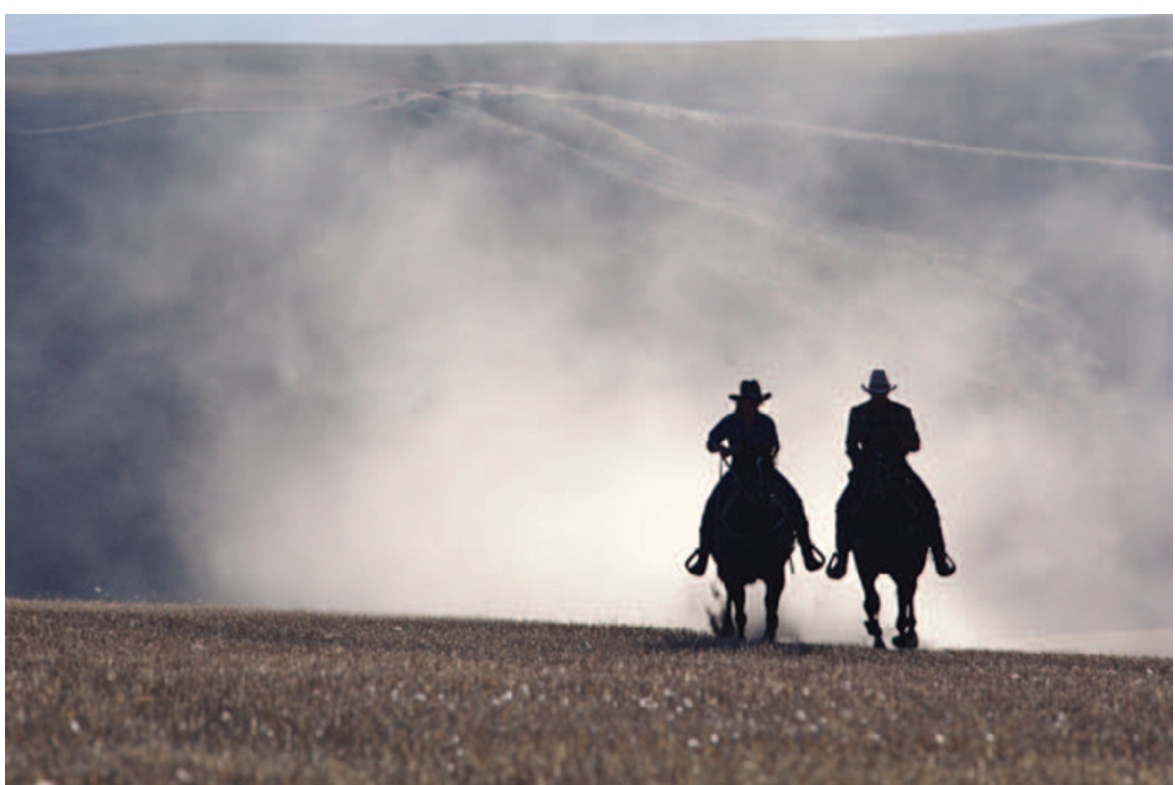

Climate models project increased drying and warming in the southwest US, indicating the region may also become dustier.

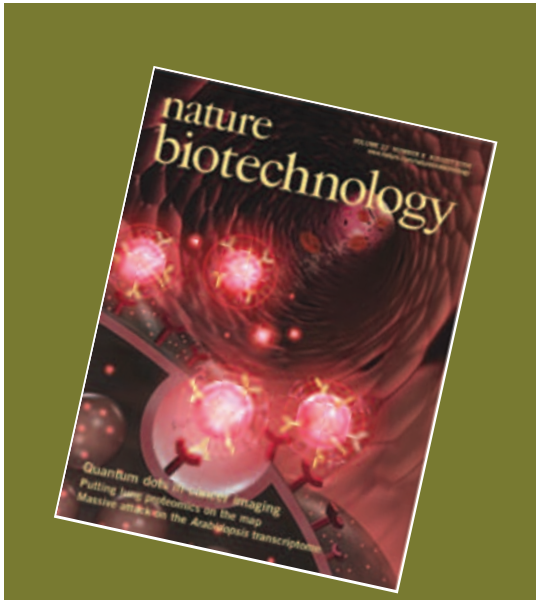

\section{Subscribe}

\section{to Nature}

\section{Biotechnology}

and get FREE

Premium Plus

\section{access to}

\section{news@ \\ nature.com}

The best in

science journalism

\section{Premium Plus access:}

- full-text access to all news

- archives back to 1998

- news collections

- Ahead of Print news publication 